\title{
DIAGNOSIS AND REPAIR OF RANDOM NOISE IN THE SENSOR'S CHRIS-PROBA
}

\author{
M.R.Mobasheri ${ }^{\mathrm{a}}$, S.A.Zendehbad ${ }^{\mathrm{b}}$ \\ ${ }^{\text {a }}$ Remote Sensing Department, Khaje Nasir Toosi University of Technology, Tehran, Islamic Republic of \\ Iran-mobasheri@kntu.ac.ir \\ ${ }^{\mathrm{b}}$ Electrical Engineering Department, Khavaran higher education institute, Mashhad, Islamic Republic of \\ Iran-zendehbad@hotmail.com
}

KEY WORDS: Sensor CHRIS, Noise, Temperature effects, Electronic effects

\begin{abstract}
:
The CHRIS sensor on the PROBA-1 satellite has imaged as push-broom way, 18 meter spatial resolution and 18 bands (1.25-11 nm) spectral resolution from earth since 2001. After 13 years of the life of the sensor because of many reasons including the influence of solar radiation and magnetic fields of Earth and Sun, behaviour of the response function of the detector exit from calibration mode and performance of some CCDs has failed. This has caused some image information in some bands have been deleted or invalid. In some images, some dark streaks or light bands in different locations need to be created to identify and correct.

In this paper all type of noise which likely impact on sensor data by CHRIS from record and transmission identified, calculated and formulated and method is presented through modifying. To do this we use the In-fight and On-ground measurements parameters. Otherwise creation of noise in images is divided into horizontal and vertical noise. Due to the random noise is created in different bands and different locations, those images in which noise is observed is used. In this paper, techniques to identify and correct the dark or pale stripe detail of the images are created. Finally, the noisy images were compared before and after the reform and effective algorithms to detect and correct errors were demonstrated.
\end{abstract}

\section{INTRODUCTION}

PROBA-1 satellite, which is considered one of the smallest satellites in addition to the CHRIS sensor HRC as a high resolution camera is mounted on it. SREM unit as well as a radiation detector is located on the satellite. Sun and Earth's magnetic fields and solar radiation over a decade of operations Satellite effects on the output of the sensor. In the upper picture, magnetic field changes belong to out of the earth atmosphere that has been most effected by solar storms. But in the bottom picture, due to the effect of the atmosphere the sun and earth magnetic field is less. These changes have the effect of magnetic fields on the CCDs is causing the error. It SREM units between 2009 and 2010 to control the temperature inside the satellite was turned off and the gray bar is created so.

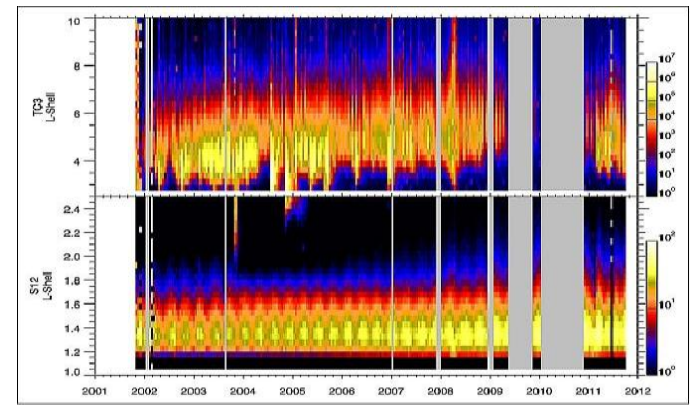

Figure 1: Effect of magnetic field of the sun and earth on

the CHRIS sensor performance between 2001 and 2012

The satellite is designed in such a way that some corrections are made on In-flight mode. These correction are flat-field calibration is done monthly by help of sun and ground stations, the monthly correction wavelength band of $760 \mathrm{~nm}$ is performed with the aid of an oxygen absorption line and the latest correction is DC offset calibration is done in Each rotation of the satellite with aim of Dark reference pixel and Smear pixel in the CCD array.

\section{CHRIS SENSOR}

CHRIS sensor is designed and made in Italy by a multi spectral sensor that works in 5 modes for different applications. This sensor is designed in such a way when the light from earth entering the telescope, guided and focused by some mirrors and passes through a small aperture. After that this light decomposition to broad spectral by charter and at all are recorded to detectors of sensor. The general characteristics of the sensor are shown in Table 1.

\begin{tabular}{|c|c|}
\hline Instrument: & push-broom imaging spectrometer \\
\hline Field of view: & $1.3^{\circ}$ \\
\hline Ground swath: & $13.5 \mathrm{~km}$ \\
\hline Altitude: & Apogee: $688 \mathrm{~km}$, perigee: $556 \mathrm{~km}$ \\
\hline Orbit inclination: & $97.8^{\circ}$ \\
\hline Descending node: & 12:10 local time \\
\hline Across track pixel size: & $18 \mathrm{~m}$ or $36 \mathrm{~m}$ \\
\hline Along track pixel size: & Finest resolution is $18 \mathrm{~m}$ \\
\hline Number of images: & $\begin{array}{c}5 \text { acquisitions of the same area at } \\
+55,+36,0,-36,-55 \text { view angles } \\
\text { during the same orbit }\end{array}$ \\
\hline Spectral range: & $410 \mathrm{~nm}$ to $1050 \mathrm{~nm}$ \\
\hline Spectral resolution: & $\begin{array}{c}\text { From1.25 nm@ @ } 400 \mathrm{~nm} \text { to } 11 \\
\text { nm@1050 nm and binning } \\
\text { possibility }\end{array}$ \\
\hline Number of spectral bands & $\begin{array}{c}\text { From } 18 \text { bands at a spatial } \\
\text { resolution of } 18 \mathrm{~m} \text {, to } 63 \text { at } 36 \mathrm{~m}\end{array}$ \\
\hline Sensor type: & $\begin{array}{c}\text { E2V CCD25-20 (1152 × 780 } \\
\text { pixels, } 25 \mu \mathrm{m} \times 25 \mu \mathrm{m} \text { pixel size, } \\
\text { full frame transfer, thinned and } \\
\text { back-illuminated })\end{array}$ \\
\hline Digitalization & 12 bits \\
\hline Signal-to-noise ratio & $\begin{array}{c}\text { max. } 250 @ \text { target albedo }=0.2, \lambda \\
=800 \mathrm{~nm} . \text { gain }=8.583\end{array}$ \\
\hline
\end{tabular}

Table 1: Specifications CHRIS sensor 


\subsection{How CHRIS sensor imaging}

This is a push broom sensor is designed in such a way that records images of each point 5 picks can be seen in Figure 2 as well. One of the issues that must be considered in this section is an error that can occur. Distance Satellite from the ground for record this 5 images is different and the distance around the Earth at different rotations may change. This is well illustrated in Figure 3. Figure 4 also shows this difference distances as a graph to its characteristics are recorded in Table 2.

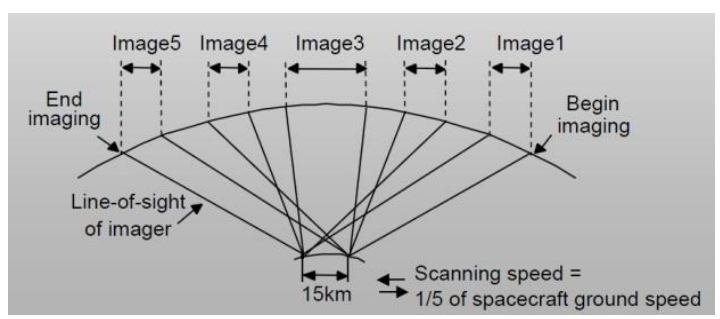

Figure 2: How the 5 images recorded by the CHRIS sensor

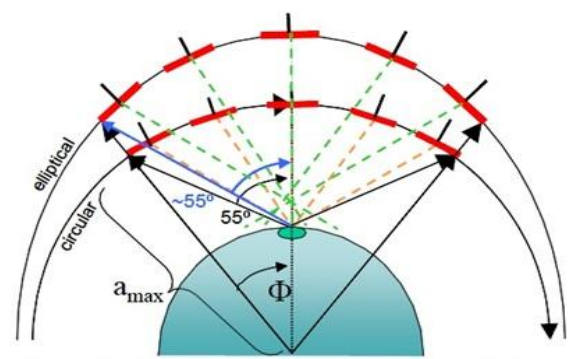

Figure 3: The axis of the oval satellite for record 5 images by CHRIS sensor

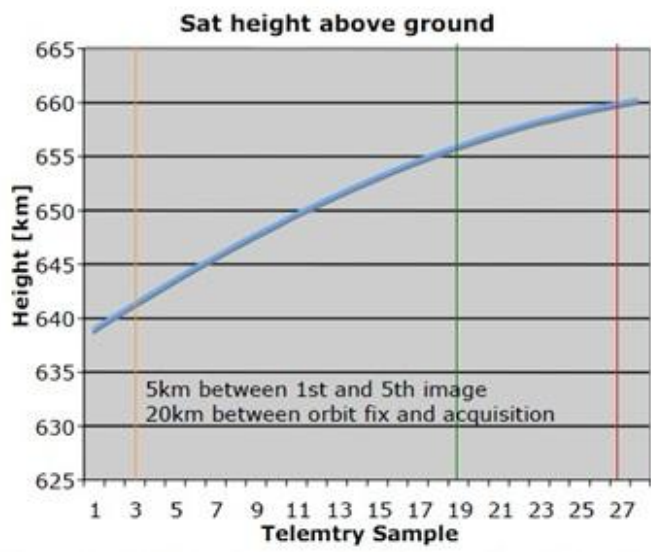

Figure 5: The difference distance between recording 5 images

\begin{tabular}{|c|c|c|}
\hline & $\begin{array}{c}\text { Max } \\
\text { altitude }\end{array}$ & $\begin{array}{c}\text { Min. } \\
\text { altitude }\end{array}$ \\
\hline \pm 55 FZA angles $\left(^{\circ}\right.$ ) & \pm 49.52 & \pm 56.18 \\
\hline \pm 36 FZA angles $\left(^{\circ}\right)$ & \pm 29.27 & \pm 32.02 \\
\hline Inclination $\left(^{\circ}\right)$ & 97.81 & 97.81 \\
\hline Period $($ min) & 98.33 & 95.596 \\
\hline Altitude (km) & 678.8 & 547.4 \\
\hline
\end{tabular}

Table 2: Maximum and minimum distance at different angles at different rotation of satellite for recording 5 images

\subsection{The CHRIS sensor response functions}

Sensor response functions in different bands visible in Figure 5. Figure 6 compares the response functions in 3 different bands. As seen at higher wavelengths, the effective band width is increased.

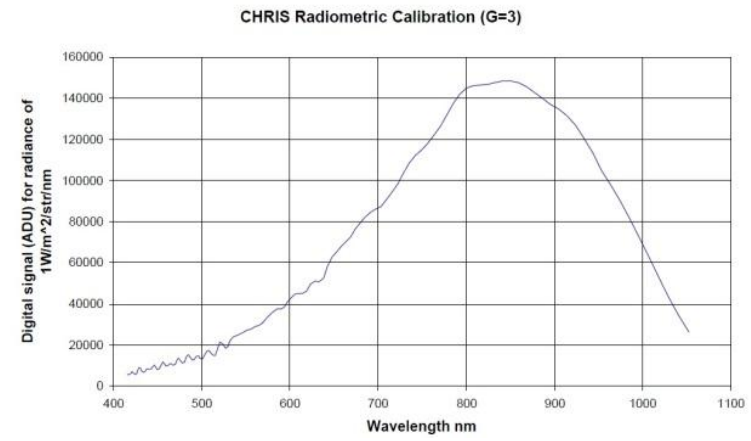

Figure 5: The CHRIS sensor response functions

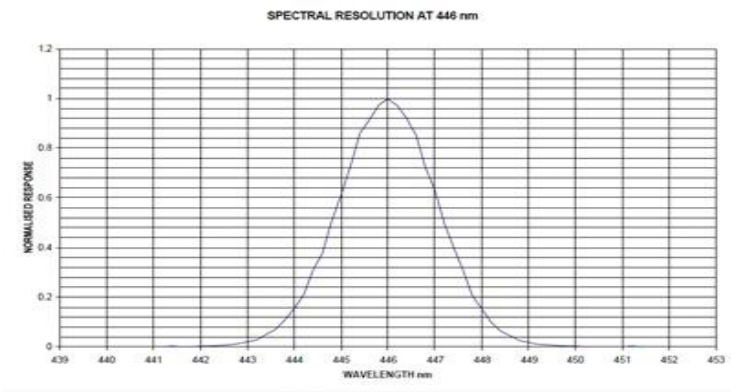

SPECTRAL RESOLUTION AT SAE n-

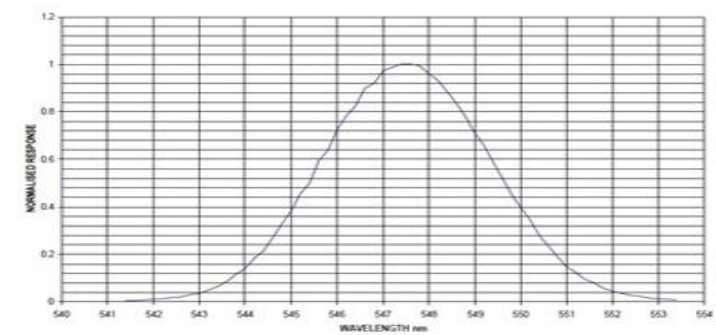

SPECTRAL RESOLUTION AT MIO $\mathrm{mm}$

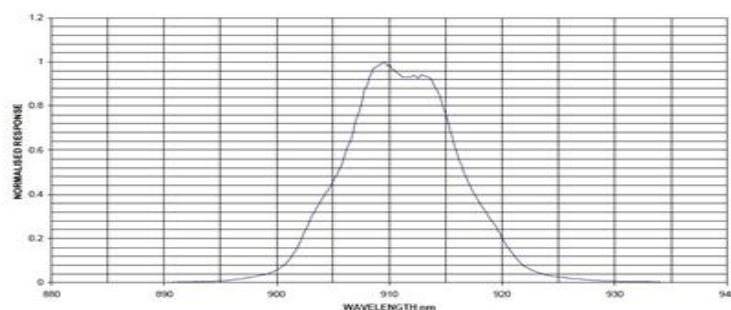

\begin{tabular}{|c|c|}
\hline Wavelength & FWHM \\
\hline $446 \mathrm{~nm}$ & 1.9 \\
\hline $546 \mathrm{~nm}$ & 3.6 \\
\hline $910 \mathrm{~nm}$ & 10.6 \\
\hline
\end{tabular}

Figure 6: Comparison of the CHRIS sensor response functions at various wavelengths and compare the effective wavelength

\section{CHRIS SENSOR ELECTRONIC NOISE}

After 13 years of the life of the sensor because of many reasons including the influence of solar radiation and magnetic fields of Earth and Sun, behavior of the response function of the detector 
calibration mode exit and performance of some CCDs has failed. This has caused some image information from a number of bands have been deleted or is invalid and in some images, some dark streaks or light bands in different locations need to be created to identify and correct.

To do this we use the In-fight measurements parameters. These parameters include: DC offset measurements, relative gain measurements, wavelength calibration, response calibration using sunlight, linearity and saturation and noise measurements. In addition to this, the parameters that are measured On-ground, including: full aperture radiometric calibration, stray light calibration, spatial resolution, spectral and spatial registration assessment, wavelength characterization (with respect to temperature), linearity and saturation and noise measurements. Noise was investigated in this paper are:

Shot noise: The noise that occurs when photon of light reaching the CCD is different. This is due to the semiconductor structure and the CCD are all not exactly the same and their performance is slightly different. This noise can be calculated from the statistical data.

Dark noise (Dark current): it seen when no light receive to CCD but CCD record some things. Although the influence of solar radiation and the Earth's magnetic belt is important but changing temperature is the main factor to create this noise.

Read noise: This noise is happen when the light is received to CCD wants to become voltage signal. Also when no light receive to detectors the output of $\mathrm{CCD}$ must be considered zero but the output value changes because of temperature again.

Round-off error: It is due to the finite ADC quantization accuracy.

Smearing effect: Last noise associated with smear noise that can occur when CCD charging.

In Table 3, all the noise is formulated and calculated and measured.

\begin{tabular}{|l|c|}
\hline Shot noise: & $\langle\sigma\rangle_{\text {photon }}=\sqrt{N_{e}} \sqrt{\tau_{\text {int }}}$ \\
\hline Dark noise: & $\langle\sigma\rangle_{\text {dark }} \sim \varsigma(T) \sqrt{\tau_{\text {int }}}$ \\
\hline Read noise: & $\left\langle\sigma>_{\text {read }}=0.1 \sqrt{N_{\text {well }}}\right.$ \\
\hline Round-off error: & $\left\langle\sigma>_{\text {round } \text {-off }}=N_{\text {well }} /\left(2^{N_{\text {bit }}} \sqrt{12}\right)\right.$ \\
\hline Smearing effect: & $\delta s\left(\lambda_{i}\right)=k\left(\tau_{\text {shift }}, \tau_{\text {int }}\right) \int_{\lambda_{i}}^{\lambda_{f}} s(\lambda) d \lambda$ \\
\hline
\end{tabular}

$\begin{array}{lc}\text { where: } & \\ N_{\text {well }}: & \text { Full well capacity } \\ N_{e} & \begin{array}{c}\text { Number of electrons generated after } \\ \text { absorption of photons }\end{array} \\ \tau_{\text {int }} & \text { Integration time } \\ \varsigma(T) & \text { Function depending } \\ N_{\text {bit }} & \text { on sensor temperature } T \\ \tau_{\text {shift }} & \text { Accuracy of digitalisation } \\ s(\lambda) & \text { Time for transferring carrier } \\ k\left(\tau_{\text {shift }}, \tau_{\text {int }}\right) & \text { from a pixel-to-pixel } \\ \lambda_{i}, \lambda_{f} & \text { Spectral response of sensor }\end{array}$

Table 3: Type of CHRIS sensor noise which has been formulated
Changing temperature is the most important factor to making noise. Due to the different seasons the varying distance between the Earth and the satellite and sun, temperature changes caused. As can be seen in Figure 7 light valves with temperature changed causing error. It means when the temperature increases the valves for light become tighter and increase noise. Also given in Table 3 , the temperature is directly related to the Dark noise.

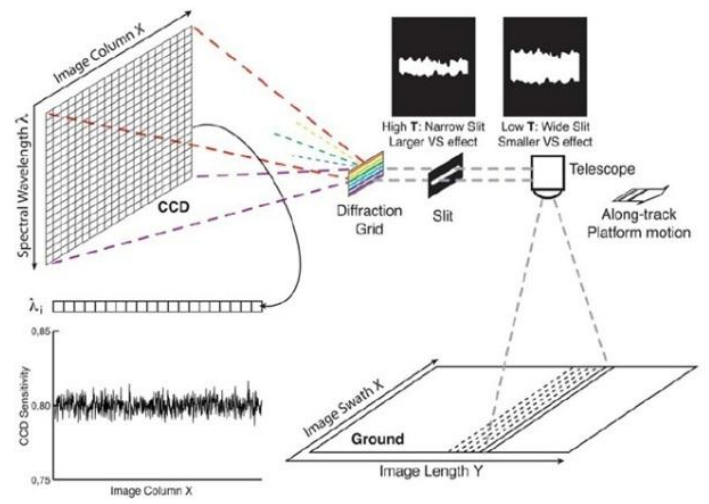

Figure 7: Effect of temperature on the CHRIS sensor noise

\subsection{Identify and correct noise}

Creation of noise in images is divided into horizontal and vertical noise. Due to the random noise is created in different bands and different locations, in this paper those images in which noise is observed is used. One of the important points that makes different horizontal noise is a row is not completely lost but it only happens for even pixels causes would facilitate this type of error correction. This type of noise can be seen in Figure 8.

To identify this kind of noise in each band we calculate average of any row. Then when there is a large change we noticed noise. As can be seen in Figure 9, the location of the noise in each band and each row can be detected. To fix it, as shown in Figure 9, by averaging of four adjacent pixels can be removed the noise.

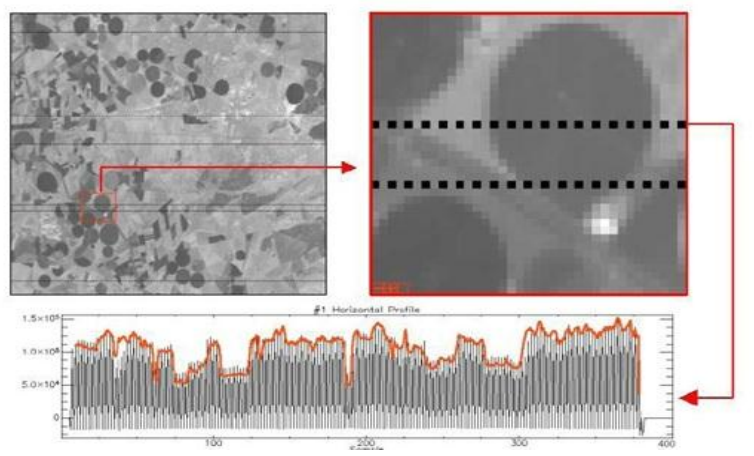

Figure 8: Horizontal noise in images captured by the CHRIS sensor 


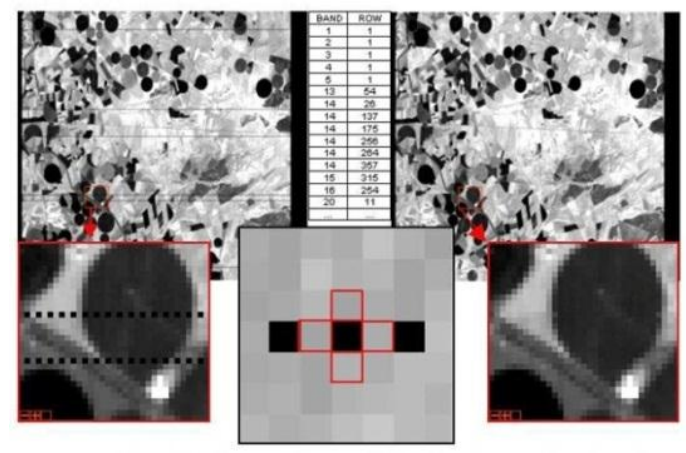

Figure 9: Identify and correct the horizontal noise in images captured by the CHRIS sensor

Vertical noise causes pale or dark strips in images it might happen in different bands and different places that there is a need to identify and correct. The picture is an example of this type of noise can be seen in Figure 10. Various algorithms can be used to identify this kind of noise the first algorithm can be seen in Figure 11. In this method, the low pass filter should be used, and finally where figure has a major change is Vertical noise there.

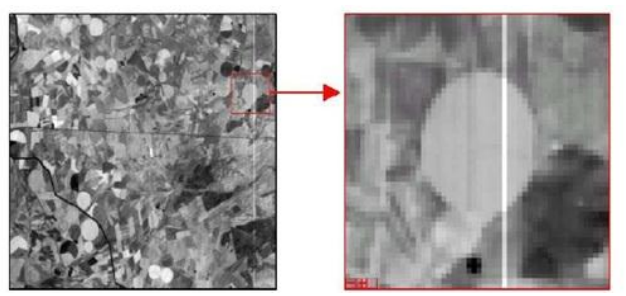

Figure 8: Vertical noise in images captured by the CHRIS sensor

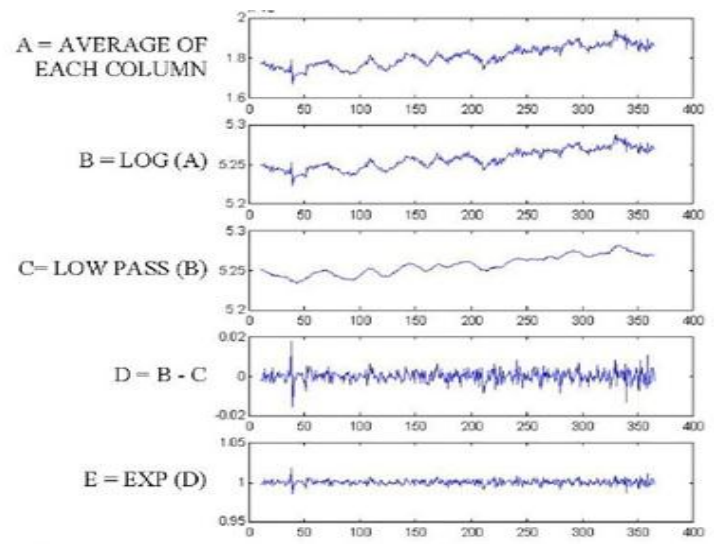

Figure 11: Vertical noise detection algorithms in CHRIS sensor image using a low-pass filter

This type of error correction methods are shown in Figure 12. As can be seen in this Figure, aid of adjacent columns is used to correct the errors. As shown in Figure 13 is the number 1 to be brought on the A and $\mathrm{C}$.

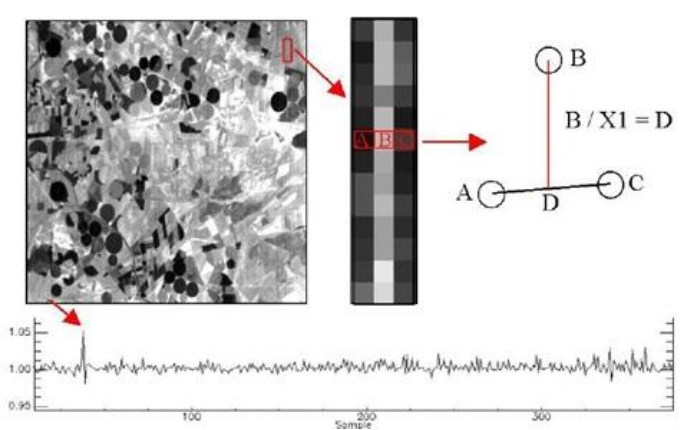

Figure 12: Vertical correction method noise created in

CHRIS sensors images by helping the adjacent columns

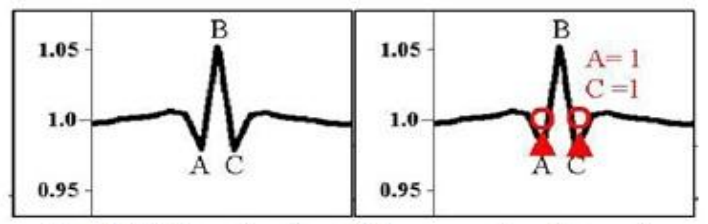

Figure 13: Correction factor for vertical noise in adjacent columns in the CHRIS sensor

In Figure 14 the five images taken at different angles of an object by CHRIS sensor are shown that has been modified by this algorithm.

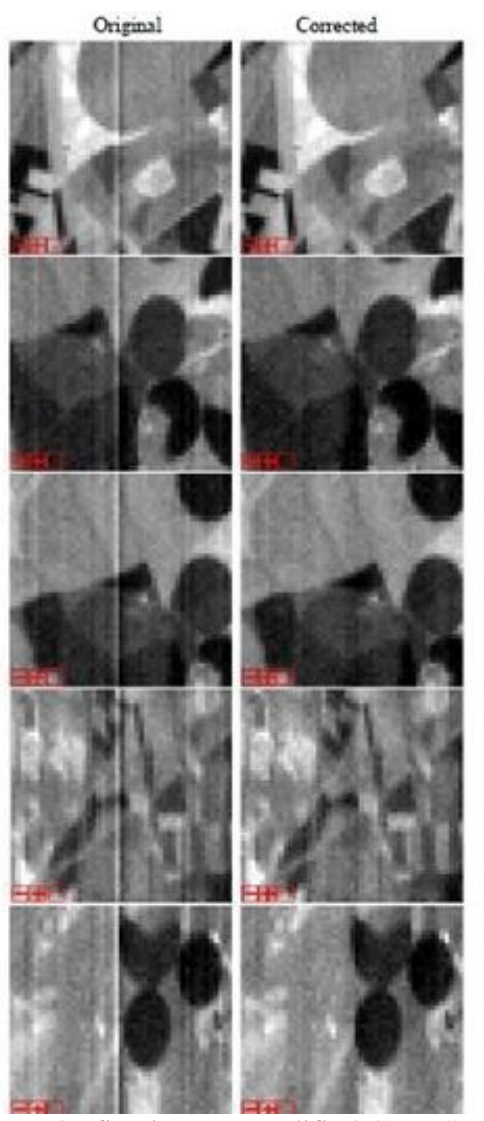

Figure (14): five images modified CHRIS sensor

In Figure 15 the image of Lebanon desert has been shown that is correct by this way. Because this place is a homogenous field it was a good place to test this algorithm. 

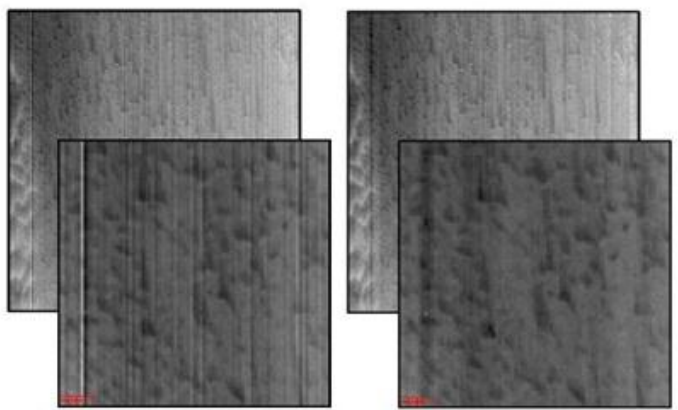

Figure 15: Modification of vertical noise in the desert Lebanon image band 10 by CHRIS sensor

One of the points that should be considered is that some bands are noisier than the other bands. For example, as you can see in Figure 16, the band 10 to band 57 is more noisy.
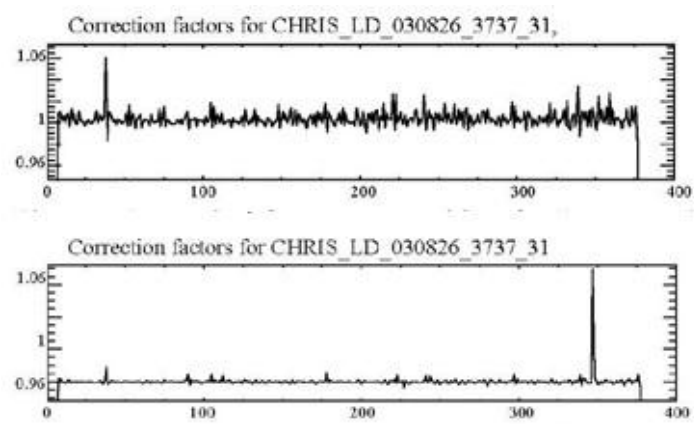

Figure 16: Comparison of noise in band 10 (pictured above) and band 57 (pictured below) in a CHRIS sensor images of lebanon Desert

The next algorithm is proposed to correct the vertical noise is shown in Figure 17. It is better than the previous algorithm does not require a low pass filter.

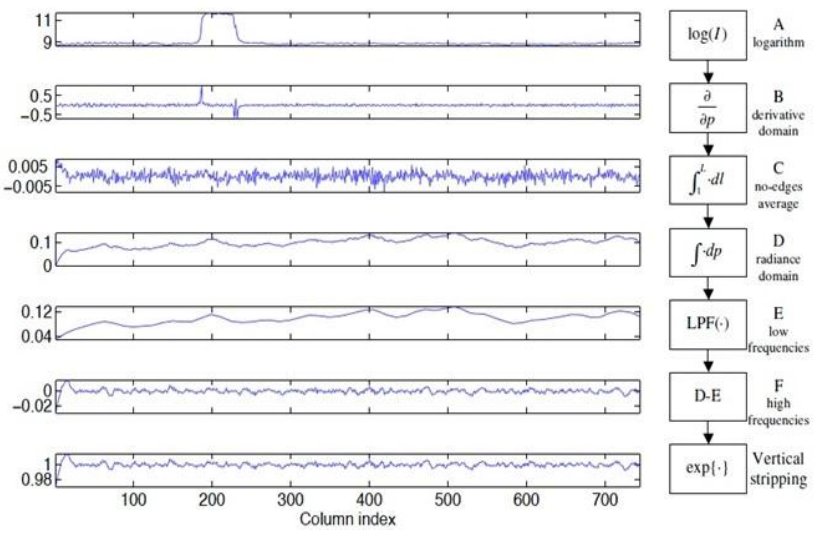

Figure 17: Algorithm to detect and correct vertical noise in CHRIS sensor

Image corrected with the help of this algorithm in Figure 18 is shown. Also in Table 4 the error value in Figure 18 is less than the standard value. Compared with the previous algorithm is also shown in Figure 19 and is seen as the new algorithm is better.
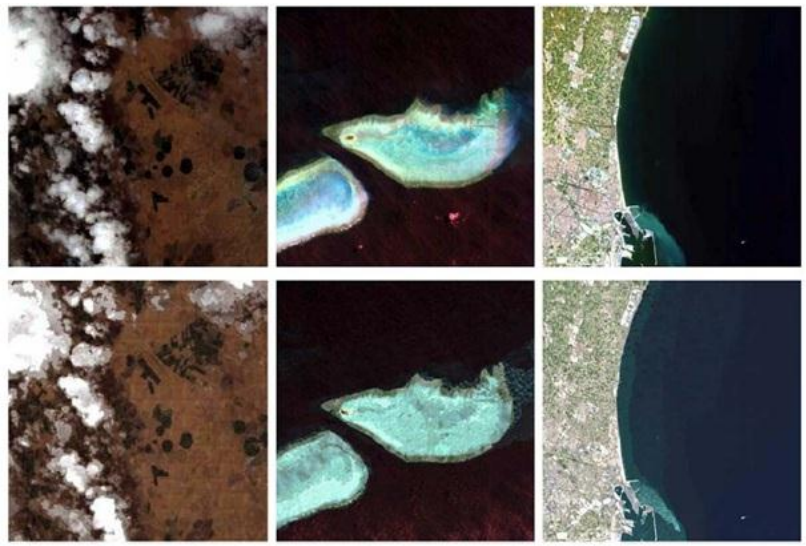

Figure (18): a new algorithm to correct the vertical noise (pictured below) with unmodified and raw image (pictured above) in CHRIS sensor images

BR-2005-07-17 (pictured left), EL-2006-01-30 (middle image), PC-2005-05-18 (pictured right)

\begin{tabular}{|c|c|c|c|c|c|c|}
\hline \multirow[b]{2}{*}{ Image Nethod } & \multicolumn{2}{|c|}{ BR.2005:-07:17 } & \multicolumn{2}{|c|}{ E1.2006-01.30 } & \multicolumn{2}{|c|}{$\mathrm{PC} 2005.05 \cdot 18$} \\
\hline & Standard & Proposed & Standard & Proposed & Standard & Proposed \\
\hline $\mathrm{ME} \times 10^{-2}$ & -0.471 & -0.429 & -0.452 & -0.398 & -0.486 & -0.413 \\
\hline $\operatorname{MAE} \times 10^{-1}$ & 0.131 & 0.127 & 0.126 & 0.120 & 0.149 & 0.145 \\
\hline RMSE $\times 10^{-3}$ & 0.104 & 0.101 & 0.132 & 0.126 & 0.198 & 0.192 \\
\hline 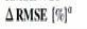 & \multicolumn{2}{|c|}{2.48} & \multicolumn{2}{|c|}{4.00} & \multicolumn{2}{|c|}{3.09} \\
\hline
\end{tabular}

Table 4: Comparison of standard noise and noise obtained from the corrected image in Figure 18
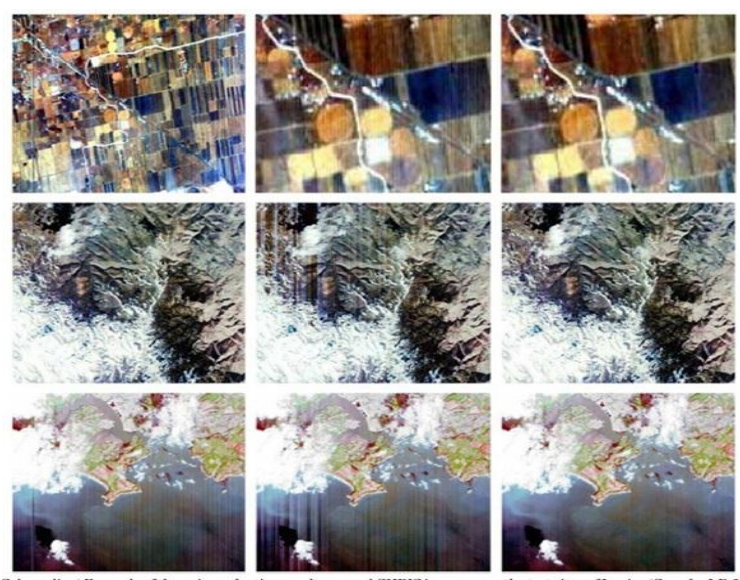

Figure 19: Comparison of the new algorithm to correct vertical noise (pictured right) and the previous algorithm (image center) and raw uncorrected image (left image) in CHRIS sensor

\section{CONCLUSION}

In this paper, after the introduction of the CHRIS sensor and how it functions, the creation of noise, type of noise and electronic noise explained. One of the main causes of error is effect of magnetic fields of the Earth and the Sun on CCD's sensor. Also the effect of temperature on noise was assessed and finally, methods to detect and repair random noises in images recorded by CHRIS sensors introduce and compared these algorithms were applied on noisy images. 


\section{REFERENCES}

Luis G'omez-Chova, Luis Alonso, Luis Guanter, Javier Calpe, Jose Moreno , 2008. "CHRIS/PROBA Noise Reduction Module" , Development of CHRIS/PROBA modules for the BEAM toolbox ESA ESRIN Contract No. 20442/07/I-LG

Luis Gómez Chova, Luis Alonso, Luis Guanter, Gustavo Camps Valls, Javier Calpe, and José Moreno , 2008. "Correction of systematic spatial noise in push-broom hyper spectral sensors: application to CHRIS/PROBA images", APPLIED OPTICS / Vol. 47, No. 28 / 1 October 2008

J.C. Garcia,J. Moreno , 2004. "REMOVAL OF NOISES IN CHRIS/PROBA IMAGES: APPLICATION TO THE SPARC CAMPAIGN DATA", Proc. of the 2nd CHRIS/Proba Workshop, ESA/ESRIN, Frascati, Italy 28-30 April (ESA SP-578, July 2004)

Alessandro Barducci, Donatella Guzzi, Paolo Marcoionni, Ivan Pippi , 2005. "CHRIS-PROBA PERFORMANCE EVALUATION:SIGNAL-TO-NOISE RATIO, INSTRUMENT EFFICIENCY AND DATA QUALITY FROM ACQUISITIONS OVER SAN ROSSORE (ITALY) TEST SITE", Proc. of the 3rd ESA CHRIS/Proba Workshop, 21-23 March, ESRIN,Frascati, Italy, (ESA SP-593, June 2005)

Luis Alonso, José Moreno , 2005" ADVANCES AND LIMITATIONS IN A PARAMETRIC GEOMETRIC CORRECTION OF CHRIS/PROBA DATA", Proc. of the 3rd ESA CHRIS/Proba Workshop, 21-23 March, ESRIN, Frascati, Italy, (ESA SP-593, June 2005)

M. A. Cutter, D. R. Lobb, T. L. Williams and R. E. Renton, 1999. "Integration \& Testing of the Compact HighResolution Imaging Spectrometer (CHRIS)", SPIE Vol 3753 July 1999, SPIE Conference Denver, USA

Mike Cutter, Dan Lobb , 2004. "DESIGN OF THE COMPACT HIGH-RESOLUTION IMAGING SPECTROMETER (CHRIS), AND FUTURE DEVELOPMENTS", Sira 5th ICSO 2004 CHRIS paper SP554

Mike Cutter , 2000. "Compact High Resolution Imaging Spectrometer (CHRIS)", sira electro-optics, SIRA4_July_2000

"PROBA-1 charting Earth's radiation belts for a decade," ESA, Nov. 7, 2011, URL:http://www.esa.int/esaMI/Proba_web_site/SEMX52T WLUG_0.html 